Proceedings of the 31th Annual Meeting of the Brazilian Embryo Technology Society (SBTE); Cabo de Santo Agostinho, PE, Brazil, August 17th to 19th, 2017.

\title{
In vitro production of bovine embryos: cumulus/granulosa cell gene expression patterns point to early atresia as beneficial for oocyte competence
}

\author{
Gianluca Mazzoni ${ }^{1,4}$, Eduardo Razza ${ }^{2}$, Hanne S. Pedersen ${ }^{3}$, Jan Secher ${ }^{1}$, Haja N. Kadarmideen ${ }^{4}$, Henrik \\ Callesen $^{3}$, Lotte Stroebech ${ }^{1,5}$, Kristine Freude ${ }^{1}$, Poul Hyttel ${ }^{1,6}$ \\ ${ }^{1}$ Department of Veterinary and Animal Sciences, University of Copenhagen, DK1870 Frederiksberg C, Denmark. \\ ${ }^{2}$ Department of Pharmacology, Institute of Bioscience, University of São Paulo State, Distrito de Rubião Junior s/n, 18618-689, \\ Botucatu, SP, Brazil. \\ ${ }^{3}$ Department of Animal Science, Aarhus University, DK8830 Tjele, Denmark. \\ ${ }^{4}$ Department of Bio and Health Informatics, Technical University of Denmark, Kgs. Lyngby, Denmark. \\ ${ }^{5}$ EmbryoTrans Biotech ApS, Koege, Denmark.
}

\begin{abstract}
In vitro production (IVP) of bovine embryos has become widespread technology implemented in cattle breeding and production. Here, we review novel data on cumulus/granulosa cell gene expression, as determined by RNAseq on cellular material from pooled follicular fluids at the single animal level, and relate these finding to previous data on oocyte developmental competence and ultrastructure. The cumulus/granulosa cell gene expression patterns indicate that early follicular atresia is associated with increased blastocyst yield and this hypothesis is supported by previous data on oocyte competence and ultrastructure.
\end{abstract}

Keywords: IVP, biomarkers, transcriptomics, granulosa cells, atresia, cattle, oocyte competence.

\section{Introduction}

In the Western World, there are increasing governmental and public demands for environmentally friendly dairy products derived under conditions securing animal health and welfare. These demands are reflected in innovation programs and proposed laws specifying production methods, but also in the increasing demands from e.g. Danish consumers for organic products resulting in a $60 \%$ higher price for the primary organic milk.

Breeding can significantly improve feedconversion efficiency and resilience and lower methaneemission in cattle (Colditz and Hine, 2016; Negussie et al., 2017). Since the beginning of 2000, novel technologies have made it possible to accelerate the rates of genetic gain in domestic cattle by genomic selection of calves (Blasco and Toro, 2014; Daetwyler et al., 2014). The association between phenotypic traits and genomic markers are getting more and more reliable and includes increasing focus on resilience and feedefficiency. Denmark is one of the leading countries with regards to correlation of phenotypes for production and health to genomic markers according to the Nordic total merit (NTM) in the form of single nucleotide polymorphisms (SNPs) using the Illumina BeadChip. Likewise, Denmark and other countries put great emphasis in registration of methane-emission in dairy cows with the prospect of identifying genomic markers for low emission (Sousa et al., 2017).

Ultrasound-guided ovum pick-up (OPU) and in vitro production (IVP) of embryos allows for a significant improved utilization of the female gene pool as multiple embryos of a specific gender can be produced from elite females. If these technologies are used on very young heifers and combined with genomic selection of the embryos, performed on a small cell biopsy before the transfer to recipients, the gain of a significant shortening of the generation interval is added (Kasinathan et al., 2015). The combined application of OPU, IVP and genomic selection has until recently posed technical challenges with respect to embryo handling and DNA amplification. However, great progress has been achieved by e.g. the EmbryoGene consortium in Canada with respect to optimization of methodologies, and the combination of OPU, IVP and genomic selection of embryos is believed to hold great promises in cattle breeding (Saadi et al., 2014).

At present, there is no commercial use of OPU/IVP in Denmark, and the application of the technologies for scientific purposes has been on hold until 2014. These restrictions have been due to the fact that bovine IVP has, over time, been hampered by impaired embryo quality resulting in the large offspring syndrome (LOS; Behboodi et al., 1995; Kruip and Den Daas, 1997; Van Wagtendonk-de Leeuw et al., 2000). Over the past years, improved formulations of the media for oocyte maturation and embryo culture have resulted in improved embryo quality, even though increased early embryo loss may still be seen over the first trimester of pregnancy (Alberto et al., 2013). Aberrant epigenetic programming, with respect to e.g. DNA methylation, is a potential factor underlying these losses (Hori et al., 2010; Chen et al., 2015). Nevertheless, IVP has become widely accepted for commercial production of bovine embryos in South and North America and parts of Europe with Denmark lacking behind.

Great advances have been done with respect to the development of media for bovine IVP, which to a great extent has eliminated LOS. However, less attention has been paid to the variable yield of competent oocytes between donor cows (Tamassia et $a l ., 2003$ ) as well as to the fact that the basal efficiency of IVP is still relatively low with only $35-45 \%$ of 
cumulus-oocyte complexes (COCs) of good morphology resulting in blastocysts (Mayes and Sirard, 2001; Sirard et al., 2006; Muñoz et al., 2014).

Transcriptomics can help in identifying biomarkers for oocyte competence (Uyar et al., 2013). In cattle, many studies have exploited the power of Next-Generation Sequencing (NGS) technologies to identify follicular biomarkers (Orozco-Lucero and Sirard, 2014). Cumulus and granulosa cells are intimately coupled to the oocyte through paracrine and intercellular communication systems and play major roles in the development of oocyte competence (Macaulay et al., 2015). Hence, these cellular compartments may reflect the quality of the oocyte and represent assessable targets for analyses, as they are aspirated together with the COCs.

Previous studies have dissected how the granulosa cell profile varies between follicles with different characteristics, for example between follicles at different developmental stages (Girard et al., 2015), between follicles of different sizes (Hatzirodos et al., 2014b) and between healthy and atretic follicles (Hatzirodos et al., 2014a). None of these studies, however, have been conducted at the single animal level to give information on the particular animal's quality as a potential oocyte donor. The aim of the present manuscript is to review our recent attempt to analyse the transcriptome of the collective cumulus/granulosa cell transcriptome of individual oocyte donor cows in order to dissect potential gene expression patterns associated with high competence of the donor for IVP (Mazzoni et al., 2017). These data are subsequently combined with previous data from our group on oocyte ultrastructure during follicular dominance and atresia in order to propose a mechanistic understanding of oocyte IVP competence (for review, see (Hyttel et al., 1997).

\section{Expression of candidate genes associated with IVP outcome at the single cow level}

In order to find associations between the collective cumulus/granulosa cell transcriptome and IVP competences within individual donor cows, COCs and follicular fluids were collected from 67 individual cows and processed for IVP including in vitro maturation, fertilization and culture (Mazzoni et al., 2017; Fig. 1). On day eight after fertilization, embryos from all animals were scored with regard to three parameters: the blastocyst rate was computed for each animal as the number of blastocysts over the total number of inseminated COCs; a kinetic score was obtained by visual classification of each blastocyst as non-expanded, expanded or hatching/hatched; and a morphology score was obtained by visual classification of each blastocyst as poor, good or excellent.

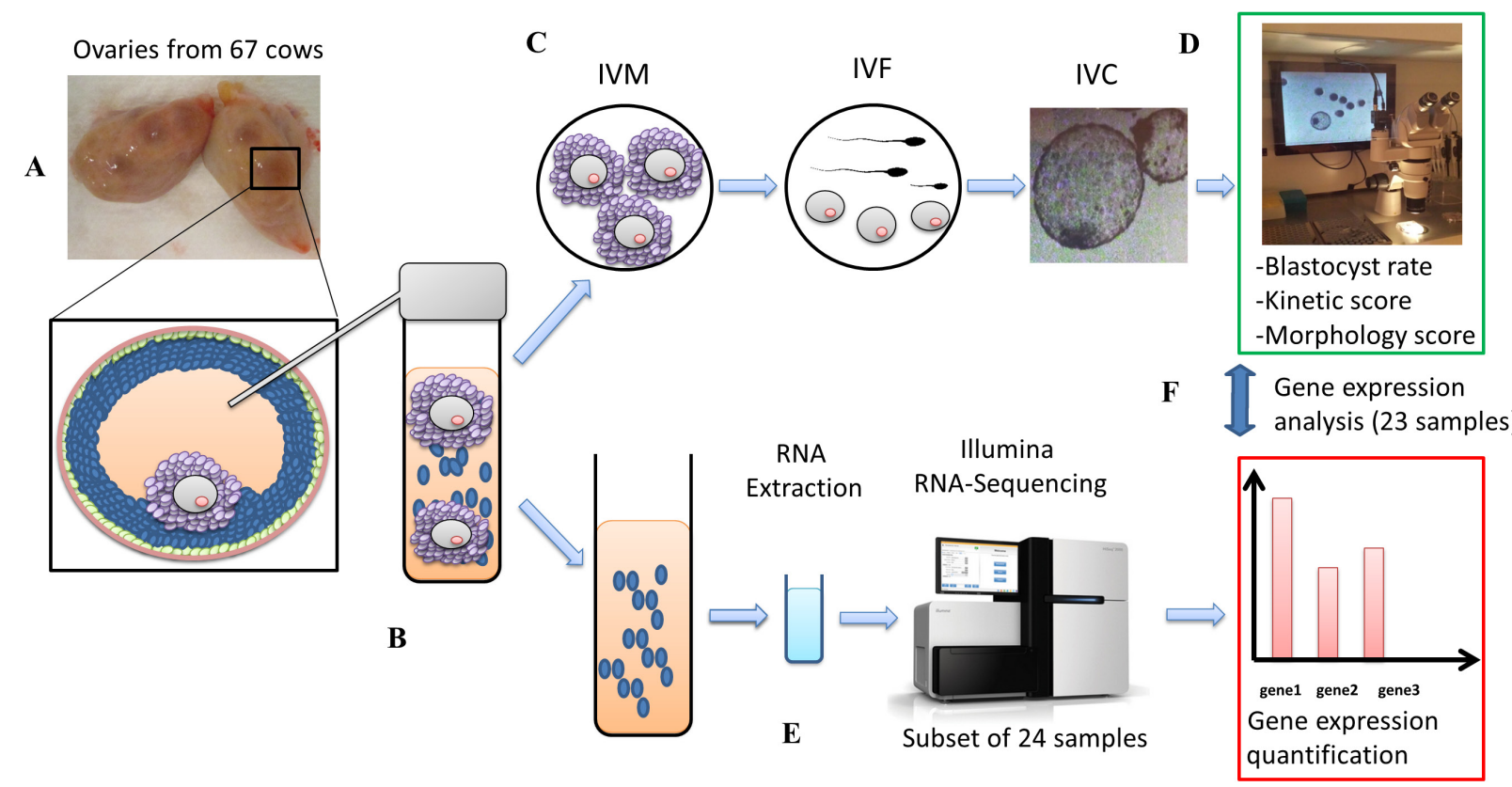

Figure 1. Experimental set-up used in Mazzoni et al. (2017). A) Ovaries from 67 Danish cows were collected after slaughter and each pair of ovaries kept separate. B) The COCs from each animal were aspirated with a vacuum pump and kept separate. C) The COCs were processed for in vitro production (IVP) including in vitro maturation (IVM), insemination (IVF) and culture (IVC) until the blastocyst (BL) stage (day 8). D) IVP parameters for each animal (BL rate, kinetics and morphology) were evaluated at day 8. E) RNA was extracted from the follicular cells contained in the aspirated fluids. A subset of 24 samples was selected and sequenced; F) RNA sequencing analysis was performed to identify genes associated with IVP performances.

Centrifuged cell pellets (cumulus/granulosa cells) from the follicular fluids were processed for RNA sequencing and bioinformatic analyses (Mazzoni et al.,
2017). For the RNA analysis, only Holstein first- or multiple-lactation cows were used and the 24 samples with higher RNA quality (RNA integrity number) were 
selected. One sample was excluded during the quality control procedure. Consequently, the final association between gene expression patterns and IVP outcome was performed on a selected group of 23 cows.

As referenced above the cumulus/granulosa transcriptome is associated with follicular status. COCs aspirated for IVP originate from follicles of a very heterogeneous background and will include dominant and subordinate follicles on ascending and descending slopes of the follicular waves (Forde et al., 2011). Interestingly, we found that two of the most important genes related to follicular development, i.e. the $\mathrm{FSH}$ receptor gene and the $\mathrm{P} 450$ aromatase gene, were expressed on average constantly across all the animals. This fact indicated that there were no systematic differences in follicular status between the animals. Hence, we consider genes that under these circumstances are correlated with IVP outcome as good candidate genes for understanding the molecular background for oocyte competence and potentially predicting the individual cows IVP outcome by identification of assessable biomarkers. The three IVP parameters were scored independently of each other. Hence, it is our hypothesis that genes significantly correlated with all three parameters are the most significant with respect to oocyte competence and potential biomarker discoveries.

The expression of seven genes was noted to be significantly associated with all three blastocyst parameters: Expression of STC1 and Mx1 were positively correlated, while expression of BEX2, RGN, HEY2, TXNDC11 and TNFAIP6 were negatively correlated with a good IVP outcome. Most of these genes have previously been found to be involved in the control of follicular development and oocyte developmental potential.

STC1 is highly expressed in both in vivo and in vitro matured oocytes (Mamo et al., 2011). The STC1 protein is secreted and exerts paracrine control of granulosa cell development, and it is expected to play a critical role in feedback loops between cumulus/granulosa and oocytes (Luo et al., 2004). A pro-apoptotic function of STC1 has previously been reported (Law et al., 2008; Guo et al., 2013).Thus, the increase of STC1 expression in cows with good IVP outcome could be associated with the presence of early atresia. Mx1 is involved in interferon signalling together with IRF and IFNAR, which were both identified as being correlated only to blastocyst rate, indicating that in particular Mx1, but also the other two genes, are of significance for oocyte competence in accordance with observations in other species including man (Lédée et al., 2008). Moreover, $\mathrm{Mx} 1$ has been reported as inducing cell death and apoptosis (Mibayashi et al., 2002). Hence, upregulation of Mx1 may consequently be associated with early atresia and, hence, improved IVP outcome (Fig. 2A)

BEX2 has previously been reported to be upregulated in large follicles as compared with their smaller counterparts (Hatzirodos et al., 2014b). BEX2 acts as an inhibitor of apoptosis in mitochondria and may, thus, prevent follicular atresia. Hence, downregulation of BEX2 may be associated with increased apoptosis and early atresia and, hence, improved IVP outcome (Fig. 2A). RGN has previously been found as highly expressed during follicular dominance and, interestingly, as acting to increase granulosa cell survival ( $\mathrm{Li}$ et al., 2016). Again, downregulation of RGN may be associated with early atresia and, hence, improved IVP outcome (Fig. 2A). HEY2 encodes a transcriptional repressor, which is a downstream target of the Notch cell signalling. Interestingly, the expression of $\mathrm{NOTCH} 2$ was significantly correlated with low blastocyst rate although no significant correlations with kinetics and morphology was noted. It may be speculated that downregulation of HEY2 and NOTCH2, and of notch signalling as such, may induce apoptosis as it has been demonstrated in mice (Zhang et al., 2011). Again, downregulation of HEY2 may consequently be associated with early atresia and, hence, improved IVP outcome (Fig. 2A).

TXNDC11 encodes a protein with the thioredoxin domain that might act as a redox regulator. TXNDC11 expression has never been associated to oocyte competence in granulosa cells, although other thioredoxin proteins have been associated with the control of ovarian follicular atresia through scavenging action on reactive oxygen species (ROS; Townson and Combelles, 2012). ROS represent one of the major contributors to oxidative damage (Cadenas and Packer, 1999; Patel et al., 1999; Turrens, 2003; Townson and Combelles, 2012) and cell death (Ott et al., 2007). We speculate that a lower expression of TXNDC11 could lead to an increase in the concentration of ROS and consequently promote atresia. Again, downregulation of TXNDC11 may be associated with early atresia and, hence, improved IVP outcome (Fig. 2A).

The expression of TNFAIP6 in granulosa cells has been correlated with decreased bovine oocyte competence after ovarian stimulation (Gilbert et al., 2012). The TNFAIP6 protein is an important component of the extracellular matrix (ECM) thanks to its hyaluronal-binding LINK domain. The ECM promotes cell survival and proliferation of granulosa cells during the follicle development in cattle (Woodruff and Shea, 2007; Salilew-Wondim et al., 2014; Ploutarchou et al., 2015). Again, downregulation of TNFAIP6 may be associated with early atresia and, hence, improved IVP outcome (Fig. 2A).

An important consideration during the selection of candidate genes encoding potential biomarkers for a particular cow's competence for IVP is the subcellular localization of their protein products. Genes whose protein products are secreted into the extracellular space (including the follicular fluid and eventually blood plasma) can potentially be measured in these fluids and used as biomarkers of IVP traits. Among the candidate genes described above, only STC1 encodes a protein, which is secreted.

\section{Gene expression patterns in relation to follicular size} and atresia

The functional analysis of the seven candidate 
genes pointed to their potential involvement in follicular atresia. Previously, gene expression in cattle has been reported in healthy $v s$. early atretic antral follicles (Hatzirodos et al., 2014a) and in small vs. medium and large follicles (Hatzirodos et al., 2014b). A comparative analysis revealed that $65 \%$ of the genes identified as differentially expressed in early atretic follicles vs. healthy follicles (Hatzirodos et al., 2014a) showed the same trend (being up- or downregulated) in our study and this percentage increased to $90 \%$ considering the top $25 \%$ of the genes positively correlated with good IVP outcome in our study (Fig. 2B). Conversely, 84\% of the genes identified as differentially expressed in medium and large follicles vs. small follicles (Hatzirodos et al., 2014b) showed the opposite trend in our study and this percentage increased to $92 \%$ when considering the top $25 \%$ genes correlated to blastocyst rate in our study. Taken together, the gene expression patterns in our study combined with the data on atresia and follicle size indicates that good IVP outcome is positively correlated with early atresia and negatively correlated with follicle size. Hence, very interestingly, this relationship points to small early atretic follicles as yielding the most competent oocytes for IVP.

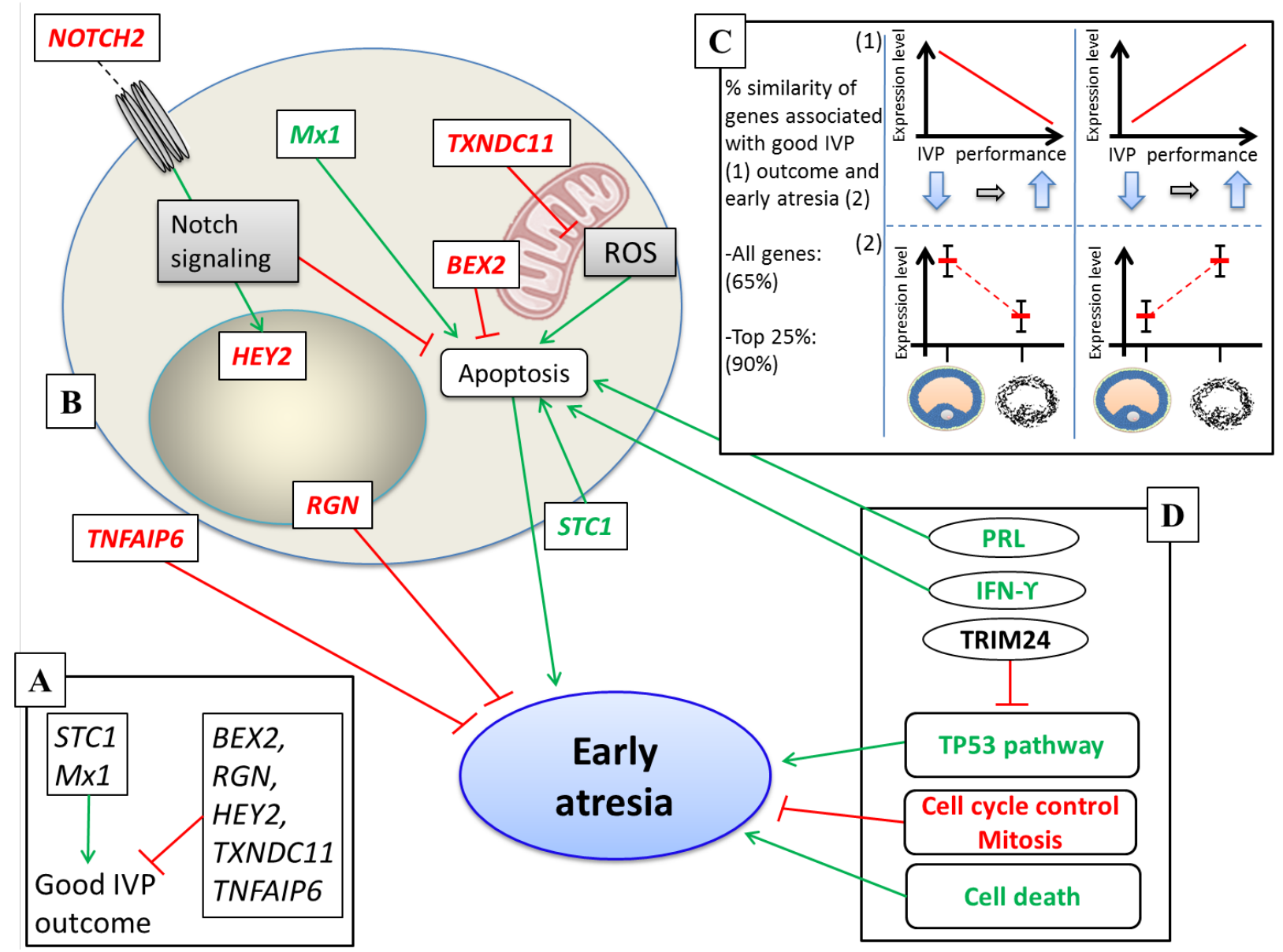

Figure 2. Summary of the evidences that lead to the hypothesis that early atresia is correlated with good IVP outcome. The figure summarizes all the bioinformatics evidences that lead to the atresia hypothesis. A) The expression level of 7 genes were significantly correlated with all parameters of a good IVP outcome: Blastocyst rate, kinetic score and morphology score. B) Schematic representation of a granulosa cell with the candidate genes and the mechanisms that support the positive correlation between early atresia and good IVP outcome. C) Representation of the comparison between the expression profiles in our study (1) and the expression profiles of atretic versus healthy follicles from Hatzirodos et al. (2014a; 2). D) Enriched pathways and upstream regulators associated with IVP outcome. Text color code: Green = positive correlation with good IVP outcome; red = negative correlation with good IVP outcome. Shape code: Rectangles = candidate genes; ovals = upstream-regulators; rounded rectangles $=$ biological processes and pathways, grey-filled rectangles $=$ molecules or molecular signalling. Arrow code: Green arrows = activation; red lines = inhibition.

\section{Pathway enrichment and upstream regulator analysis associated with follicular atresia}

Functional pathway enrichment analysis can identify biological functions and pathways overrepresented in the set of genes associated with a certain trait of interest. Functional analysis with Ingenuity ${ }^{\circledR}$ Pathway suite $\left(\right.$ IPA $\left.^{\circledR}\right)$ predicts the activation state (activated or inhibited) of the biological processes and of the main upstream regulators for the genes associated with a specific trait of interest. Functional enrichment was performed to extract biological insight 
related to the IVP process from the gene expression profiles and provided new evidences sustaining the relationship between small early atretic follicles and good IVP outcome. Hence, several biological pathways or processes were identified as being of significance for the IVP outcome. In details, processes for the control of cell proliferation and development (mitosis, cell cycle control) were negatively correlated with good IVP outcome while cell death process and the TP53 pathway were positively correlated with good IVP outcome (Fig. 2C).

The upstream regulator analysis was performed to identify key proteins responsible for the control of the expression of the genes that we found associated with good IVP outcome. Therefore, even if the expression of the upstream regulators was not identified in our dataset as being absolutely differentially expressed they indirectly represent potential candidate proteins for IVP outcome. The important upstream regulators of genes associated with good IVP outcome were TRIM24, PRL and IFN-Y (Fig. 2C).

TRIM24 was identified as an upstream repressor of TP53 promoting the degradation of this protein. Hence, TRIM24 is thought to prevent TP53induced apoptosis and, thus, atresia. The TP53 pathway is specifically interesting as it is upregulated at apoptosis (Fridman and Lowe, 2003) and has been identified as being activated when bovine growing follicles enter the plateau phase of the follicular wave and initiate atresia (Nivet et al., 2013). Hence, upregulation of the TP53 pathway may consequently be associated with early atresia and, hence, improved IVP outcome (Fig. 2C).

PRL or prolactin was predicted as being activated in cows with good IVP outcome by the upstream regulator analysis with IPA ${ }^{\circledR}$ The activation of the PRL pathway has previously been reported as positively correlated with oocyte competence (Nivet et $a l ., 2013$ ) and with the occurrence of atresia (Lebedeva et al., 1998). In the rat, PRL administration has on the one hand resulted in an increased number of atretic follicles in vivo (Besnard et al., 2001) and, on the other hand, in a decrease in the abundance of granulosa cells in late stages of cell death in vitro (Lebedeva et al., 1998; Heleil et al., 2010) combined with an increase in embryo development to the morula and blastocyst stages (Kuz'mina et al., 2001). Again, upregulation of the PRL pathway may consequently be associated with early atresia and, hence, improved IVP outcome (Fig. 2C).

The expression of IFN- $\gamma$ was not observed in our granulosa cell samples. However, the upstream regulator analysis with $\mathrm{IPA}^{\circledR}$ predicted IFN- $\gamma$ to be activated. Within the ovary, IFN- $\gamma$ is only synthesized by immune cells (Best et al., 1995). The protein enhances apoptosis and it has been found exclusively in atretic follicles in human (Best et al., 1995; Best and Hill, 2000). Again, upregulation of the IFN- $\gamma$ pathway may consequently be associated with early atresia and, hence, improved IVP outcome (Fig. 2C).

Interestingly, we found that activation of the immune system was negatively correlated with good IVP outcome. We speculate that immune system activation is related to late atresia whereas the early atresia has not yet activated this type of response. This is partially confirmed by previous studies in human, where immune cells and, in particular, macrophages are abundantly recruited within the follicles at an advanced stage of atresia (Petrovská et al., 1996; Takaya et al., 1997; Gaytan et al., 1998). Again, this speculation supports the notion that early atresia, but not late atresia, is positively correlated with good IVP outcome.

However, macrophages have also been found to be present in healthy follicles and their abundance increases during follicle growth (Wu et al., 2004). It has been suggested that macrophages promote granulosa proliferation (Fukumatsu et al., 1992) or atresia by regulating the balance between cellular proliferation and apoptosis through the secretion of factors like TNFa (Kaipia et al., 1996; Wu et al., 2004) or IFN- $\gamma$ (Mazzoni et al., 2017) as previously described. These mechanisms are still debated and must be addressed in future studies.

\section{Oocyte ultrastructure and early atresia}

The theory that early atresia is associated with good IVP outcome has been addressed earlier (Moor and Trounson, 1977; Wurth and Kruip, 1992; Feng et al., 2007) and it has directly been demonstrated that embryo yield is positively correlated with early atresia whereas late atresia has a negative impact (De Wit et al., 2000). Accordingly, the developmental potential of oocytes has earlier been reported as being positively correlated with granulosa cell apoptosis, which is widely used to identify atretic follicles (Feng et al., 2007; Heleil et al., 2010).

Along this line, previous ultrastructural studies performed in our lab also point to potential underlying explanations of the positive correlation between good IVP outcome and early atresia. Hence, studies of the ultrastructure of oocytes from dominant follicles approaching ovulation has clearly demonstrated that initial cumulus cell expansion and gradual retraction of the cumulus cell processes, attached to the oocyte through the zona pellucida, are initiated even prior to the LH peak (Assey et al., 1994). These somatic cell modulations are associated with changes in the oocyte nucleus, i.e. the germinal vesicle, which develops undulations of the nuclear envelope, likewise prior to the LH peak. After the LH peak these processes culminate in resumption of meiosis and progress of cytoplasmic oocyte maturation over a $24 \mathrm{~h}$ period leading to ovulation. We also found that the abovedescribed sequence of processes can be observed in oocytes in the subordinate follicles of the follicular wave, i.e. follicles representing early atresia. Hence, in early atretic follicles, the oocyte apparently undergoes processes that mimic those seen in the dominant follicle approaching ovulation. Seen in this light, it is not surprising that oocytes harvested from early atretic follicles may be better qualified for entering final maturation in vitro as they may be "primed" for the process, whereas oocytes from healthy growing follicles are totally locked in meiosis and may experience problems in an immediate resumption of this process 
when placed at IVM. Interestingly, coasting has been demonstrated to increase IVP embryo yield (Nivet et al., 2013); an effect that is likely also to be based upon initiation of early atresia in the follicular pool.

One approach to deal with the problem that oocytes may not be "primed" for IVM directly upon aspiration has been to induce a temporary arrest of oocyte maturation (Lonergan et al., 2003; Donnay et al., 2004; Vigneron et al., 2004). Years later, this concept was launched again through a specially designed medium, referred to as simulated physiological oocyte maturation (Albuz et al., 2010). The results have been varying, and a modified second version is now being tested (Gilchrist et al., 2015), illustrating that a practical solution to such a complex challenge is not always so easy. A dissection of this phenomenon is presently being concluded in another branch of the BrazilianDanish GIFT project (Razza et al., 2016).

\section{Conclusions}

Cumulus/granulosa cell gene expression patterns indicate that early atresia is associated with increased blastocyst yield and this hypothesis is supported by previous data on oocyte competence and ultrastructure.

\section{Acknowledgments}

Authors acknowledge the funding from the Programme Commission on Health, Food and Welfare of the Danish Council for Strategic Research for the GIFT project (www.gift.ku.dk) and from grant \#2012/50533-2, São Paulo Research Foundation (FAPESP). HNK acknowledges EU-FP7 Marie Curie Actions - Career Integration Grant (CIG-293511) for funding part of his time spent on this article.

\section{References}

Alberto ML, Meirelles FV, Perecin F, Ambrósio CE, Favaron PO, Franciolli AL, Mess AM, Santos, JM, Rici RE, Bertolini M. 2013. Development of bovine embryos derived from reproductive techniques. Reprod Fertil Dev, 25:907-917.

Albuz F, Sasseville M, Lane M, Armstrong, D, Thompson J, Gilchrist R. 2010. Simulated physiological oocyte maturation (SPOM): a novel in vitro maturation system that substantially improves embryo yield and pregnancy outcomes. Hum Reprod, 25:2999-3011.

Assey R, Hyttel P, Greve T, Purwantara B. 1994 Oocyte morphology in dominant and subordinate follicles. Mol Reprod Dev, 37:335-344.

Behboodi E, Anderson G, BonDurant R, Cargill S, Kreuscher B, Medrano J, Murray J. 1995. Birth of large calves that developed from in vitro-derived bovine embryos. Theriogenology, 44:227-232.

Besnard N, Horne E, Whitehead S. 2001. Prolactin and lipopolysaccharide treatment increased apoptosis and atresia in rat ovarian follicles. Acta Physiol, 172:1725.
Best CL, Griffin PM, Hill JA. 1995. Interferon gamma inhibits luteinized human granulosa cell steroid production in vitro. Am J Obstet Gynecol, 172:15051510.

Best CL, Hill JA. 2000. Cytokines in ovarian function. In: Hill JA (Ed.). Cytokines in Human Reproduction. New York: Wiley-Liss. pp. 43-77.

Blasco A, Toro MA. 2014. A short critical history of the application of genomics to animal breeding. Livest Sci, 166:4-9.

Cadenas E, Packer L (Ed.). 1999. Understanding the Process of Aging: The Roles of Mitochondria: Free Radicals, and Antioxidants. Boca Raton, FL: CRC Press. 384 pp.

Chen Z, Hagen DE, Elsik CG, Ji T, Morris CJ, Moon LE, Rivera RM. 2015. Characterization of global loss of imprinting in fetal overgrowth syndrome induced by assisted reproduction. Proc Nat Acad Sci, 112:4618-4623.

Colditz IG, Hine BC. 2016. Resilience in farm animals: biology, management, breeding and implications for animal welfare. Anim Prod Sci, 56:1961-1983.

Daetwyler HD, Capitan A, Pausch H, Stothard P, Van Binsbergen R, Brøndum RF, Liao X, Djari A, Rodriguez SC, Grohs C. 2014. Whole-genome sequencing of 234 bulls facilitates mapping of monogenic and complex traits in cattle. Nat Genet, 46:858-865.

De Wit A, Wurth Y, Kruip T. 2000. Effect of ovarian phase and follicle quality on morphology and developmental capacity of the bovine cumulus-oocyte complex. J Anim Sci, 78:1277-1283.

Donnay I, Faerge I, Grøndahl C, Verhaeghe B, Sayoud H, Ponderato N, Galli C, Lazzari G. 2004. Effect of prematuration, meiosis activating sterol and enriched maturation medium on the nuclear maturation and competence to development of calf oocytes. Theriogenology, 62:1093-1107.

Feng W-G, Sui H-S, Han Z-B, Chang Z-L, Zhou P, Liu D-J, Bao S, Tan J-H. 2007. Effects of follicular atresia and size on the developmental competence of bovine oocytes: a study using the well-in-drop culture system. Theriogenology, 67:1339-1350.

Forde N, Beltman M, Lonergan P, Diskin M, Roche J, Crowe M. 2011. Oestrous cycles in Bos taurus cattle. Anim Reprod Sci, 124:163-169.

Fridman JS, Lowe SW. 2003. Control of apoptosis by p53. Oncogene, 22:9030-9040.

Fukumatsu Y, Katabuchi H, Naito M, Takeya M, Takahashi K, Okamura H. 1992. Effect of macrophages on proliferation of granulosa cells in the ovary in rats. $J$ Reprod Fertil, 96:241-249.

Gaytan F, Morales C, Bellido C, Aguilar E, SanchezCriado J. 1998. Ovarian follicle macrophages: is follicular atresia in the immature rat a macrophagemediated event? Biol Reprod, 58:52-59.

Gilbert I, Robert C, Vigneault C, Blondin P, Sirard M-A. 2012. Impact of the LH surge on granulosa cell transcript levels as markers of oocyte developmental competence in cattle. Reproduction, 143:735-747.

Gilchrist R, Zeng H, Wang X, Richani D, Smitz J, 
Thompson J. 2015. Reevaluation and evolution of the simulated physiological oocyte maturation system. Theriogenology, 84:656-657.

Girard A, Dufort I, Douville G, Sirard M-A. 2015. Global gene expression in granulosa cells of growing, plateau and atretic dominant follicles in cattle. Reprod Biol Endocrinol, 13:17. doi: 10.1186/s12958-015-00107.

Guo F, Li Y, Wang J, Li Y, Li Y, Li G. 2013. Stanniocalcin1 (STC1) inhibits cell proliferation and invasion of cervical cancer cells. PloS One, 8:e53989.

Hatzirodos N, Hummitzsch K, Irving-Rodgers HF, Harland ML, Morris SE, Rodgers RJ. 2014a. Transcriptome profiling of granulosa cells from bovine ovarian follicles during atresia. BMC Genomics, 15, 40 . doi: 10.1186/1471-2164-15-40.

Hatzirodos N, Irving-Rodgers HF, Hummitzsch K, Harland ML, Morris SE, Rodgers RJ. 2014b. Transcriptome profiling of granulosa cells of bovine ovarian follicles during growth from small to large antral sizes. BMC Genomics, 15:24. doi: 10.1186/14712164-15-24

Heleil B, Kuzmina T, Alm H, Scotti O, Tuchscherer A, Torner H. 2010. Involvement of granulosa cells in realization of prolactin effects on the developmental competence of bovine oocytes matured in vitro. $J \mathrm{Am}$ Sci, 6:796-805

Hori N, Nagai M, Hirayama M, Hirai T, Matsuda K, Hayashi M, Tanaka T, Ozawa T, Horike S-I. 2010. Aberrant $\mathrm{CpG}$ methylation of the imprinting control region KvDMR1 detected in assisted reproductive technology-produced calves and pathogenesis of large offspring syndrome. Anim Reprod Sci, 122:303-312.

Hyttel P, Fair T, Callesen H, Greve T. 1997. Oocyte growth, capacitation and final maturation in cattle. Theriogenology, 47:23-32.

Kaipia A, Chun S-Y, Eisenhauer K, Hsueh A. 1996 Tumor necrosis factor-alpha and its second messenger, ceramide, stimulate apoptosis in cultured ovarian follicles. Endocrinology, 137:4864-4870.

Kasinathan P, Wei H, Xiang T, Molina JA, Metzger J, Broek D, Kasinathan S, Faber DC, Allan MF 2015. Acceleration of genetic gain in cattle by reduction of generation interval. Sci Rep, 5:8674. doi: 10.1038/srep08674.

Kruip TA, Den Daas J. 1997. In vitro produced and cloned embryos: effects on pregnancy, parturition and offspring. Theriogenology, 47:43-52.

Kuz'mina T, Lebedeva IY, Torner H, Alm H. 2001 Effects of prolactin in different culture systems on the maturation of bovine oocytes and their capacity for subsequent development. Russ J Dev Biol, , 32:112-118. Law A, Lai K, Lui W, Wan H, Wong CK. 2008. Histone deacetylase inhibitor-induced cellular apoptosis involves stanniocalcin-1 activation. Exp Cell Res, 314:2975-2984.

Lebedeva IY, Denisenko VY, Lebedev V, Kuzmina T. 1998. Prolactin in follicular fluid and intracellular store calcium in follicular cells are related to morphological signs of ovarian follicle atresia in cows: work in progress. Theriogenology, 49:509-519.

Lédée N, Lombroso R, Lombardelli L, Selva J,
Dubanchet S, Chaouat G, Frankenne F, Foidart JM, Maggi E, Romagnani S. 2008. Cytokines and chemokines in follicular fluids and potential of the corresponding embryo: the role of granulocyte colonystimulating factor. Hum Reprod, 23:2001-2009.

Li P, Meng J, Liu W, Smith GW, Yao J, Lyu L. 2016. Transcriptome analysis of bovine ovarian follicles at predeviation and onset of deviation stages of a follicular wave. Int J Genomics, 2016:9pp

Lonergan P, Gutiérrez-Adán A, Rizos D, Pintado B, De La Fuente J, Boland MP. 2003. Relative messenger RNA abundance in bovine oocytes collected in vitro or in vivo before and $20 \mathrm{hr}$ after the preovulatory luteinizing hormone surge. Mol Reprod Dev, 66:297-305.

Luo C-W, Kawamura K, Klein C, Hsueh AJ. 2004.

Paracrine regulation of ovarian granulosa cell differentiation by stanniocalcin (STC) 1: mediation through specific STC1 receptors. Mol Endocrinol, 18:2085-2096.

Macaulay AD, Gilbert I, Scantland S, Fournier E, Ashkar F, Bastien A, Saadi HAS, Gagné D, Sirard M-A, Khandjian ÉW, Richard FJ, Hytte P, Robert C. 2015. Cumulus cell transcripts transit to the bovine oocyte in preparation for maturation. Biol Reprod, 94:16. doi: 10.1095/biolreprod.114.127571.

Mamo S, Carter F, Lonergan P, Leal CL, Al Naib A, McGettigan P, Mehta JP, Evans AC, Fair T. 2011. Sequential analysis of global gene expression profiles in immature and in vitro matured bovine oocytes: potential molecular markers of oocyte maturation. BMC Genomics, 12:151. doi: 10.1186/1471-2164-12-151.

Mayes M, Sirard M. 2001. The influence of cumulusoocyte complex morphology and meiotic inhibitors on the kinetics of nuclear maturation in cattle. Theriogenology, 55:911-922.

Mazzoni G, Salleh SM, Freude K, Pedersen HS, Stroebech L, Callesen H, Hyttel P, Kadarmideen HN. 2017. Identification of potential biomarkers in donor cows for in vitro embryo production by granulosa cell transcriptomics. PloS One, 12:e175464.

Mibayashi M, Nakade K, Nagata K. 2002. Promoted cell death of cells expressing human MxA by influenza virus infection. Microbiol Immunol, 46:29-36.

Moor R, Trounson A. 1977. Hormonal and follicular factors affecting maturation of sheep oocytes in vitro and their subsequent developmental capacity. $J$ Reprod Fertil, 49:101-109.

Muñoz M, Uyar A, Correia E, Díez C, FernandezGonzalez A, Caamaño J, Martínez-Bello D, Trigal B, Humblot P, Ponsart C. 2014. Prediction of pregnancy viability in bovine in vitro-produced embryos and recipient plasma with Fourier transform infrared spectroscopy. J Dairy Sci, 97:5497-5507.

Negussie E, Lehtinen J, Mäntysaari P, Bayat A, Liinamo A-E, Mäntysaari E, Lidauer M. 2017. Noninvasive individual methane measurement in dairy cows. Animal, 11:890-899.

Nivet A-L, Vigneault C, Blondin P, Sirard M-A. 2013. Changes in granulosa cells' gene expression associated with increased oocyte competence in bovine. Reproduction, 145:555-565. 
Orozco-Lucero E, Sirard M. 2014. Molecular markers of fertility in cattle oocytes and embryos: progress and challenges. Anim Reprod, 11:183-194.

Ott M, Gogvadze V, Orrenius S, Zhivotovsky B. 2007. Mitochondria, oxidative stress and cell death. Apoptosis, 12:913-922.

Patel RP, Cornwell T, Darley-Usmar VM. 1999. The biochemistry of nitric oxide and peroxynitrite: implications. In: Cadenas E, Packer L (Ed.). Understanding the Process of Aging: The Roles of Mitochondria: Free Radicals, and Antioxidants. Boca Raton, FL: CRC Press. pp. 39-56.

Petrovská M, Dimitrov DG, Michael SD. 1996 Quantitative changes in macrophage distribution in normal mouse ovary over the course of the estrous cycle examined with an image analysis system. Am J Reprod Immunol, 36:175-183.

Ploutarchou P, Melo P, Day AJ, Milner CM, Williams SA. 2015. Molecular analysis of the cumulus matrix: insights from mice with O-glycan-deficient oocytes. Reproduction, 149:533-543.

Razza E, Pedersen H, Stroebech L, Machado M, Nogueira M, Kadarmideen H, Callesen H, Hyttel P. 2016. 192 Prematuration of bovine cumulus-oocyte complexes with cyclic adenosine monophosphate modulators affects both oocyte and blastocyst ultrastructure. Reprod Fertil Dev, 28:227. (abstract).

Saadi HAS, Vigneault C, Sargolzaei M, Gagné D, Fournier É, de Montera B, Chesnais J, Blondin P, Robert C. 2014. Impact of whole-genome amplification on the reliability of pre-transfer cattle embryo breeding value estimates. BMC Genomics, 15:889.

Salilew-Wondim D, Ahmad I, Gebremedhn S, Sahadevan S, Hossain MM, Rings F, Hoelker M, Tholen E, Neuhoff C, Looft C. 2014. The expression pattern of microRNAs in granulosa cells of subordinate and dominant follicles during the early luteal phase of the bovine estrous cycle. PloS One, 9:e106795.

Sirard M-A, Richard F, Blondin P, Robert C. 2006. Contribution of the oocyte to embryo quality. Theriogenology, 65:126-136.

Sousa RV, Silva Cardoso CR, Butzke G, Dode MAN, Rumpf R, Franco MM. 2017. Biopsy of bovine embryos produced in vivo and in vitro does not affect pregnancy rates. Theriogenology, 90:25-31.
Takaya R, Fukaya T, Sasano H, Suzuki T, Tamura M, Yajima A. 1997. Macrophages in normal cycling human ovaries; immunohistochemical localization and characterization. Hum Reprod, 12:1508-1512.

Tamassia M, Heyman Y, Lavergne Y, Richard C, Gelin V, Renard J, Chastant-Maillard S. 2003. Evidence of oocyte donor cow effect over oocyte production and embryo development in vitro. Reproduction, 126:629-637.

Townson DH, Combelles CM. 2012. Ovarian follicular atresia. In: Darwis A. (Ed.). Basic Gynecology - Some Related Issues. Rijeka, Croatia: In Tech. pp. 43-76. Available on: www.intechopen.com/ /books/basicgynecology-some-related-issues/ovarian-follicularatresia.

Turrens JF. 2003. Mitochondrial formation of reactive oxygen species. J Physiol, 552:335-344.

Uyar A, Torrealday S, Seli E. 2013. Cumulus and granulosa cell markers of oocyte and embryo quality. Fertil Steril, 99:979-997.

Van Wagtendonk-de Leeuw A, Mullaart E, De Roos A, Merton J, Den Daas J, Kemp B, De Ruigh L. 2000. Effects of different reproduction techniques: AI, MOET or IVP, on health and welfare of bovine offspring. Theriogenology, 53:575-597.

Vigneron C, Perreau C, Dupont J, Uzbekova S, Prigent C, Mermillod P. 2004. Several signaling pathways are involved in the control of cattle oocyte maturation. Mol Reprod Dev, 69:466-474.

Woodruff TK, Shea LD. 2007. The role of the extracellular matrix in ovarian follicle development. Reprod Sci, 14:6-10.

Wu R, Van der Hoek KH, Ryan NK, Norman RJ, Robker RL. 2004. Macrophage contributions to ovarian function. Hum Reprod Update, 10:119-133.

Wurth Y, Kruip TA. 1992. Bovine embryo production in vitro after selection of the follicles and oocytes. In: Proceedings of the 12th International Congress on Animal Reproduction. The Hague, The Netherlands: ICAR. pp. 387-389.

Zhang C-P, Yang J-L., Zhang J, Li L, Huang L, Ji SY, Hu Z-Y, Gao F, Liu Y-X. 2011. Notch signaling is involved in ovarian follicle development by regulating granulosa cell proliferation. Endocrinology, 152:24372447. 